\title{
The Accuracy of Ultrasonography in the Diagnosis of Fetal Head Engagement
}

\author{
Zakia M Ibrahim, Waleed A Sayed Ahmed, Mohamed A Elmorsy, Magda M Albiely and Omima T Taha* \\ Department of Obstetrics and Gynecology, Egypt \\ *Corresponding author: Omima T Taha, Department of Obstetrics and Gynecology, Faculty of Medicine, Suez Canal University, \\ Round Road, Ismailia 41111, Egypt
}

\section{ARTICLE INFO \\ Received: 幽 January 11, 2020 \\ Published: 慧 January 23, 2020 \\ Citation: Zakia M Ibrahim, Waleed A Sayed Ahmed, Mohamed A Elmorsy, Magda M Albiely, Omima T Taha. The Accuracy of Ultrasonography in the Diagnosis of Fetal Head Engagement. Biomed J Sci \& Tech Res 24(5)-2020. BJSTR. MS.ID.004119.}

Keywords: Abdominal ultrasound; Digital vaginal examination; Fetal head engagement; Perineal ultrasound; Vaginal delivery

\begin{abstract}
A successful vaginal birth is the art of obstetrics. Many concerns exist regarding this event that raises patients' anxiety. The main concern is the possibility of having a successful vaginal delivery. Many methods are present to detect fetal head engagement, which plays a significant role in the event of vaginal birth. The digital vaginal examination was the first method to diagnose it. However, it has been stated that digital vaginal examination was painful, causing great distress to patients. This study aimed at evaluation of the accuracy of three different modalities in the diagnosis of fetal head engagement using transabdominal ultrasound, transperineal ultrasound, and digital vaginal examination. This was a cross-sectional analytical study carried out in the emergency and delivery ward of the obstetrics and gynecology department of Suez Canal university hospitals from January 2018 to June 2019. We recruited sixty-six nulliparous women and the examination was carried out while in the latent phase of labor. The mean age was $29.2 \pm 1.5$, and the gestational age had a median of 38 weeks.

The fetal head engagement was diagnosed in $60(90.0 \%)$ of patients using transvaginal digital examination. The fetal head engagement was documented in 55 patients only by transabdominal ultrasound, with a percent agreement of $91.7 \%$ and a p-value of 0.0001 . Occipitoanterior position was recorded in $59 / 66$ patients $(89.4 \%)$. The head-perineum distance was reported to be $52.2 \mathrm{~mm} \pm 6.1$. The fetal head engagement was reported in $56 / 66(84.8 \%)$ patients, with a percent agreement of $93.3 \%$ and a p-value of 0.0001 . A head - perineum distance of $60 \mathrm{~mm}$ had a sensitivity and specificity of $100 \%$ and $91 \%$ in the prediction of fetal head engagement, respectively. Transperineal ultrasound was more accurate to detect fetal head engagement. It also had a high sensitivity and specificity when using the head- perineum distance.
\end{abstract}

\section{Introduction}

There are two paramount queries in the philosophy of labor: when and how to deliver. The answer to these questions is extremely hard. Besides, the pregnant woman is very anxious about her chances of having a vaginal delivery or a cesarean birth. We must consider other risk factors that may import a sudden modification in the course of labor with our aim to maintain maternal and fetal safety [1]. Previous researches showed that digital vaginal examination (DVE) might fail to identify fetal head position accurately. In these situations, ultrasound proved to be more effective [2], with a reduced error in the diagnosis of fetal head position and progression especially during labor [3]. Fetal head engagement is defined as the passage of the biparietal diameter from the pelvic inlet [4]. This commonly occurs in nulliparous women from gestational age 36 weeks, while most of them will present in labor with the head not engaged [5]. The role of intrapartum ultrasound was previously reported to be useful in certain circumstances such as before the use of instrumental delivery [6]. Intrapartum ultrasound was found to be more accurate with less discomfort than digital vaginal examination [2]. The current study aimed at comparing the accuracy of three methods of diagnosing fetal head engagement (digital vaginal examination, transabdominal ultrasound, and transvaginal ultrasound). 


\section{Patients and Methods}

This was a cross-sectional analytical study. It was conducted in the labor and delivery ward of the obstetrics and gynecology department, Suez Canal university hospitals from January 2018 to June 2019. Patients were recruited according to the following inclusion criteria: a) Age 18-35years old, b) Primigravida, c) Singleton fetus, d) Cephalic presentation, e) gestational age $\geq 37$ weeks, and f) in the latent phase of labor. Patients who refused to participate in the study or to continue with the study protocol were excluded. Eligible patients were subjected to the following: a) History taking, including personal data, menstrual history to confirm the gestational age, and symptoms of fetal head engagement (frequency of micturition, difficulty in walking, rectal tenesmus, lightening), b) Clinical examination included a general examination and abdominal examination. On abdominal examination, fetal head engagement was documented when only two-fifths of the fetal head was palpable [7]. Alternatively, when the BPD of the fetus has descended through the pelvic inlet, the examining fingers cannot reach the lowermost part of the fetal head; as a result when pushed down over the abdomen the examining fingers slide over that portion of the fetal head proximal to the BPD and diverge. Conversely, if the fetal head is not engaged, the examining fingers can easily palpate the lower part of the fetal head and will converge (the fourth Leopold maneuver) [8] (Tables 2 \& 3).

Finally, a local examination was done with digital pelvic examination (assessment of pelvic capacity, confirm presentation, confirm position, detect engagement and station, detect degree of deflection). On transvaginal assessment, engagement of the fetal head was considered to have usually (but not always) occurred when the presenting part (typically the parietal bone) was positioned at maternal ischial spine station [9] (Table 4).

\section{Ultrasound Examination was Performed}

Transabdominal Ultrasonography (TAS): Initially, the patient was placed in a sitting position and the level of the lumbar vertebrae L5 and S1 (sacral promontory) was demarcated (utilizing the posterior superior iliac spines and superior aspect of the median sacral crest) [10]. The woman was later placed in a supine position, to demarcate the pelvic inlet, and the transabdominal transducer was placed transversely above the symphysis pubis and directed cephalad towards the maternal sacral promontory. The sacral promontory, although not visible sonographically due to the presence of the fetal skull, is considered to be positioned between L5 and S1, i.e. at the level marked previously [11]. Utilizing midline intracranial structures (cavum septum pellucidum, falx cerebri, and thalami), the level of the BPD was ascertained. When the BPD was located below the line extending between the superior aspect of the maternal symphysis pubis and the maternal sacral promontory (demarcating the pelvic inlet), the fetal head was considered to be engaged; conversely it was not engaged when the BPD was depicted at an angle above the pelvic inlet.

Transperineal Ultrasonography (TPS): It was performed with the woman in a supine position and with an empty bladder. The shortest distance from the outer bony limit of the fetal skull to the skin surface of the perineum was measured in a transverse view, with the probe held over the ischial tuberosity with firm pressure, but without creating any discomfort to the woman. This distance was measured in all women. The midpoint of the pelvic canal is at the level of the ischial spine. The distance from the perineum to the ischial spine is $5 \mathrm{~cm}$, according to the World Health Organization (WHO) stages of head descent. The fetal head-perineum distance was measured by transperineal ultrasound imaging as the shortest distance from the outer bony limit of the fetal skull to the skin surface of the perineum [12]. Both ultrasound methods were compared to findings obtained on vaginal palpation of the fetal head. Examiners were blinded to each other's results.

\section{Results}

The mean age was $29.2 \pm 1.5$, and the gestational age had a median of 38 weeks. The fetal head engagement was diagnosed in $60(90.0 \%)$ of patients using transvaginal digital examination (Table 1). Using trans-abdominal ultrasound, fetal head engagement was documented in 55 patients only, with a percent agreement of $91.7 \%$ and a p-value of 0.0001 (Table 2). Occipitoanterior position was recorded in 59/66 patients (89.4\%) (Table 3). The perineal head distance was reported to be $52.2 \mathrm{~mm} \pm 6.1$ (Table 4). The fetal head engagement was reported in 56/66 (84.8\%) patients, with a percent agreement of $93.3 \%$ and a p-value of 0.0001 . A head - perineum distance of $60 \mathrm{~mm}$ had a sensitivity and specificity of $100 \%$ and $91 \%$ in the prediction of fetal head engagement, respectively (Tables 5 and 6).

Table 1: Relation of engagement as detected by DVE to fetal head position and mode of delivery.

\begin{tabular}{|c|c|c|c|c|}
\hline \multicolumn{2}{|c|}{} & Engaged n= 60 (90.9\%) & Not engaged n= 6 (9.1\%) & P -value \\
\hline \multirow{2}{*}{ Fetal head position (DVE) } & OA & $57(95 \%)$ & $2(33.3 \%)$ & \multirow{2}{*}{0.0001} \\
\cline { 2 - 4 } & OP & $3(5 \%)$ & $4(66.7 \%)$ & \\
\hline \multirow{2}{*}{ Mode of delivery (DVE) } & Vaginal delivery & $52(86.7 \%)$ & $2(33.3 \%)$ & \multirow{2}{*}{0.0001} \\
\cline { 2 - 4 } & CS & $8(13.3 \%)$ & $4(66.7 \%)$ & \\
\hline
\end{tabular}


Table 2: Agreement between fetal head engagement as detected by DVE and TAS.

\begin{tabular}{|c|c|c|c|c|c|}
\hline & \multicolumn{3}{|c|}{ TAS } & \multirow{2}{*}{$P$-value } \\
\hline & & Engaged & Not engaged & Total & \\
\hline \multirow[t]{3}{*}{ DVE } & Engaged & 55 & 5 & 60 & \multirow{3}{*}{0.0001} \\
\hline & Not engaged & 0 & 6 & 6 & \\
\hline & Total & 55 & 11 & 66 & \\
\hline
\end{tabular}

Table 3: Relation of engagement as detected by TAS and head position and mode of delivery.

\begin{tabular}{|c|c|c|c|c|}
\hline & & Engaged $\mathbf{N}=\mathbf{5 5}$ & $\begin{array}{c}\text { Not engaged } \\
\mathbf{N = 1 1}\end{array}$ & \multirow{2}{*}{-value } \\
\hline Fetal position & OA & 53 & 6 & \multirow{2}{*}{0.0001} \\
\hline & OP & 2 & 5 & \multirow{2}{*}{0.0001} \\
\hline Mode of delivery & NVD & 47 & 7 & \\
\hline & CS & 8 & 4 & 6 \\
\hline
\end{tabular}

Table 4: Perineum-fetal head distance as detected by transperineal ultrasound (TPS).

\begin{tabular}{|c|c|c|c|}
\hline \multicolumn{2}{|c|}{ Perineum-fetal head distance (mm) } & Range & $34-67$ \\
\cline { 3 - 4 } & Mean \pm SD & $\mathbf{5 2 . 2} \pm \mathbf{6 . 1}$ \\
\hline \multirow{2}{*}{ Head engagement } & Engaged & No (\%) & $56(84.8 \%)$ \\
\cline { 2 - 4 } & Not engaged & No (\%) & $10(15.2 \%)$ \\
\hline
\end{tabular}

Table 5: Cut-off, sensitivity, specificity, positive predictive value, negative predictive value and accuracy of perineum-fetal head distance for the prediction of fetal head engagement.

\begin{tabular}{|c|c|}
\hline Cut-off & $\mathbf{6 0} \mathbf{~ m m}$ \\
\hline Sensitivity & $100 \%$ \\
\hline Specificity & $91 \%$ \\
\hline Positive predictive value & $98 \%$ \\
\hline Negative predictive value & $100 \%$ \\
\hline Accuracy & $98.50 \%$ \\
\hline
\end{tabular}

Table 6: Agreement between fetal head engagement as detected by DVE and TPS.

\begin{tabular}{|c|c|c|c|c|c|c|}
\hline \multicolumn{2}{|c|}{} & \multicolumn{3}{|c|}{ TPS } & $\begin{array}{c}\text { Kappa } \\
\text { test }\end{array}$ & \\
\cline { 3 - 7 } & \multicolumn{2}{|c|}{} & $\kappa$ & P \\
\cline { 3 - 7 } & Engaged & $\begin{array}{c}\text { Not } \\
\text { engaged }\end{array}$ & Total & & \\
\hline DVE & Engaged & 55 & 5 & 60 & 0.58 & 0.0001 \\
\hline & Not engaged & 1 & 5 & 6 & & \\
\hline & Total & 56 & 10 & 66 & & \\
\hline
\end{tabular}

\section{Discussion}

We recruited nulliparous patients with a mean age of $29.2 \pm 1.5$ and a median gestational age of 38 weeks. The fetal head engagement was diagnosed in 60 (90.0\%) of patients using transvaginal digital examination. Using trans-abdominal ultrasound, fetal head engagement was documented in 55 patients only, with a percent agreement of $91.7 \%$ and a p-value of 0.0001 . A slightly higher percentage was reported using transperineal ultrasound (56 patients, with a percent agreement of 93.3\% and a p-value of 0.0001). This was higher than what was published in a previous study [2]. This could be attributed to the difference in the studied population as the study above recruited nulliparous women as well as multiparous ones while the current study recruited nulliparous women only. Occipitoanterior position was the predominant fetal head position occurring in 59/66 patients (89.4\%). This was higher than what was reported by Akmal et al. (65.6\%). This would be explained by performing digital vaginal examination by consultant level specialists in $17 \%$ of cases $(n=11)$ or by trainees with different years of experience in obstetrics and gynecology, with a resultant failure to identify fetal head position in $26.6 \%$ of cases [6]. "However; digital vaginal examination was performed by senior specialists only in this study.

The fetal head engagement was ascertained in 57/60 (95\%), $53 / 55$ (96.4\%) patients with an occiput anterior position using digital vaginal examination and trans-abdominal ultrasound, respectively. This was higher than previous study in which accurate determination of fetal head station was documented in $75 \%$ of patients. The accuracy increases in cases with occiput anterior position and when the head is below the level of the ischial spines [6]. The fetal head engagement was documented in 52/60 (86.7\%), 47/ 55 (85.5\%) patients who delivered vaginally, using digital vaginal examination and trans-abdominal ultrasound respectively. Transperineal ultrasound was comfortable to perform and tolerable for the patients as reported previously [13]. The head- perineum distance was said to be $52.2 \mathrm{~mm} \pm 6.1$. The fetal head engagement was reported in 56/66 (84.8\%) patients, with a percent agreement of $93.3 \%$ and a p-value of 0.0001 . A head - perineum distance of $60 \mathrm{~mm}$ had a sensitivity and specificity of $100 \%$ and $91 \%$ in the prediction of fetal head engagement, respectively. This study compared the above mentioned three methods for fetal head engagement with the transperineal ultrasound reported to be more accurate. A more extensive meta-analysis needs to be conducted to draw reliable recommendations from the previous studies. Obstetricians should be trained on performing transperineal ultrasound to determine fetal head position and engagement especially when the bony landmarks are obscured. The recruitment of multiparous women should be recommended with further subanalysis of the accuracy of these modalities with different parities.

\section{Conclusion}

Transperineal ultrasound was more accurate to detect fetal head engagement. It also had high sensitivity and specificity when using the head-perineum distance.

\section{Conflicts of Interest}

None.

\section{Ethical Approval}

All procedures performed in in the study were in accordance with the ethical standards of the institutional and/or national 
research committee and with the 1964 Helsinki declaration and its later amendments or comparable ethical standards. This article did not contain any studies with animals performed by any of the authors.

\section{Informed Consent}

was obtained from all participants before enrollment in the study.

\section{Funding}

This was self-funded research

\section{References}

1. Tinelli A, Ma Y, Gustapane S, Malvasi A (2019) Intrapartum ultrasound during prolonged second stage of labor: a diagnostic tool suggested for operative delivery to reduce complications. Journal of inter Disciplinary Research Applied to Medicine JDREAM 2(2): 43-52.

2. Sherer DM, Miodovnik M, Bradley KS, Langer O (2002) Intra-partum Fetal Head Position II: Com-parison between Transvaginal Digital Examination and Transabdominal Ul-trasound Assessment during the Second Stage of Labor. Ultrasound in Obstet-rics and Gynecology 19(3): 264-268.

3. Malvasi A, Giacci F, Gustapane S, Sparic R, Barbera A, et al. (2016) Intrapartum Sonographic Signs: New Di-agnostic Tools in Malposition and Mal-rotation. The Journal of Maternal-Fetal \& Neonatal Medicine: The Official Journal of the European Association of Perinatal Medicine, the Federation of Asia and Oceania Perinatal Societies, the International Society of Perinatal Obstetricians 29(15): 2408-2413.

4. Norwitz ER, Robinson JN, Repke JT (2001) Labor and delivery. In Obstetrics: Normal and Problem Pregnancies ( $4^{\text {th }}$ edn.). Gabbe SG, Niebyl JR, Simpson JL (Edn's.), Churchill Livingstone: New York, USA, pp. 353394.

\section{ISSN: 2574-1241}

DOI: 10.26717/BJSTR.2020.24.004119

Omima T Taha. Biomed J Sci \& Tech Res

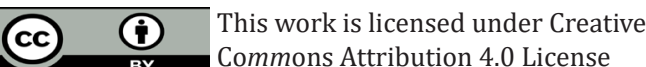

Submission Link: https://biomedres.us/submit-manuscript.php
5. Sherer DM, Abulafia O (2003) Intrapartum assessment of fetal head engagement: comparison between transvaginal digital and transabdominal ultrasound determinations. Ultrasound Obstet Gynecol 21(5): 430-436.

6. Akmal S, Kametas N, Tsoi E, Hargreave C, Nicolaides KH, et al. (2003) Comparison of transvaginal digital examination with intrapartum sonography to determine fetal head position before instrumental delivery. Ultrasound Obstet Gynecol 21(5): 437-440.

7. Cunningham FG, Gant NF, Leveno KJ (2001) Mechanisms of normal labor. In Williams Obstetrics ( $21^{\text {st }}$ edn.). McGraw Hill: New York, USA, pp. 291307.

8. Cunningham FG, Gant NF, Leveno KJ (2001) Anatomy of the reproductive tract. In Williams Obstetrics (21 $1^{\text {st }}$ edn.). McGraw Hill: New York, USA, p. 31-61.

9. Norwitz ER, Robinson JN, Repke JT (2001) Labor and delivery. In: Obstetrics: Normal and Problem Pregnancies (4 ${ }^{\text {th }}$ edn.). GabbeSG, NiebylJR, SimpsonJL (Eds.), Churchill Livingstone: New York, USA, pp. 353-394.

10. Netter FH (1987) Vertebral column and pelvis. In the CIBA Collection of Medical Illustrations. Musculoskeletal system. Part I; Anatomy, Physiology and Metabolic Disorders. CIBA-GEIGY Corporation: West Caldwell NJ 8: 9-19.

11. WilliamsPL, WarwickR, Dyson M (1989) The pelvis. In Gray's Anatomy (37 ${ }^{\text {th }}$ edn.), Churchill Livingstone: Edinburgh, pp. 428-434.

12. Rane SM, Guirgis RR, Higgins B (2005) Models for the prediction of successful induction of labor based on pre-induction sonographic measurement of fetal head-perineum distance. Matern Fetal Neonatal Med 17(5): 315-322.

13. Barbera AF, Pombar X, Perugino G, Lezotte DC, Hobbins JC, et al. (2009) A new method to assess fetal head descent in labor with transperineal ultrasound. Ultrasound Obstet Gynecol 33(3): 313-319.

$\begin{array}{ll}\text { BIOMEDICAL } & \text { Assets of Publishing with us } \\ \text { RESEARCHES } & \text { - Global archiving of articles } \\ \text { - Immediate, unrestricted online access } \\ \text { - Rigorous Peer Review Process }\end{array}$

